\title{
Effect of housing type on health and performance of preweaned dairy calves during summer in Florida ${ }^{1}$
}

\author{
G. Peña, ${ }^{*}$ C. Risco, ${ }^{*}$ E. Kunihiro, ${ }^{*}$ M-J. Thatcher, ${ }^{*}$ and P. J. Pinedot ${ }^{2,3}$ \\ *Department of Large Animal Clinical Sciences, College of Veterinary Medicine, University of Florida, Gainesville 32610 \\ †Texas A\&M AgriLife Research \& Extension Center, College of Veterinary Medicine and Biomedical Sciences, Texas A\&M University System, \\ Amarillo 79106
}

\section{ABSTRACT}

The objective was to evaluate the effect of housing type on health and performance of preweaned dairy calves. One hundred calves, Holsteins (HO) or Holstein-Jersey crosses (HJ), were randomly assigned to a Calf-Tel (L. T. Hampel Corp., Germantown, WI) polyethylene hutch exposed to direct sun light $(\mathrm{n}=25$ for both $\mathrm{HO}$ and $\mathrm{HJ}$ ) or a wire hutch with a plywood shade located under trees $(\mathrm{n}=24$ and 26 for $\mathrm{HO}$ and HJ, respectively). Calf rectal temperature, respiratory rate, health scores, and weaning weight were compared by housing type. Rectal temperatures were higher in calves in Calf-Tel hutches compared with calves in wire hutches at $1500 \mathrm{~h}$, at $40.1 \pm 0.28$ and $39.1 \pm 0.22^{\circ} \mathrm{C}$, respectively. Similarly, respiratory rates were higher in calves in Calf-Tel hutches compared with calves in wire hutches at $1500 \mathrm{~h}$, at $90 \pm 15$ and $65 \pm 10$ breaths per minute, respectively. Frequencies of calves presenting abnormal ear scores did not differ between calves in Calf-Tel or wire hutches. Abnormal eye scores were less likely to occur for calves in the wire hutches. Frequencies of calves with signs of respiratory disease, such as nasal discharge and coughing, were higher in the wire hutches compared with the Calf-Tel hutches. No differences were noted in the incidence and time of first diarrhea event in calves between hutch types. Calves in wire hutches had 5.47 greater odds of receiving veterinary treatment compared with calves in the Calf-Tel hutches. Weaning weights were not different for calves in Calf-Tel or in wire hutches. The lower frequency of calves with abnormal health scores and receiving veterinary treatment in Calf-Tel hutches and the lack

\footnotetext{
Received July 23, 2015.

Accepted October 14, 2015.

${ }^{1}$ Mention of a trade name does not imply an endorsement or recommendation by the University of Florida over similar companies or products not mentioned.

${ }^{2}$ Corresponding author: pablo.pinedo@colostate.edu

${ }^{3}$ Current address: Department of Animal Sciences, Colorado State University, Fort Collins 80523.
}

of difference in weight gain suggests that this housing system adapted well to the specific environmental conditions of this study.

Key words: calves, health, housing, performance

\section{INTRODUCTION}

Housing type and environment play a pivotal role in the health and behavior of dairy calves (NAHMS, 2007). The most favorable housing for dairy calves depends upon climatic conditions, as calf growth and health are affected by cold and hot weather (Collier et al., 1982; Young, 1983; Broucek et al., 2009). As described by Donovan (1992), an appropriate calf housing environment should be clean, dry, and well ventilated. As individual hutches excel in these recommendations and provide isolation of calves, they are commonly used in calf-rearing programs (Broucek et al., 2009).

A common housing system used in warm humid environments is a wire-framed hutch with a piece of plywood on top to provide shade. Although this type of hutch design has been successfully used in the southeast region of the United States, during summer months calves may experience heat stress due to inappropriate shade. Consequently, many producers choose to raise calves inside open ventilated barns or underneath trees. Another calf hutch design option available to dairy producers is the Calf-Tel (L. T. Hampel Corp., Germantown, WI) housing system. The Calf-Tel hutch is completely enclosed with polyethylene-based plastic, which provides shade and, because of its adjustable rear ventilation door, may be adequate for warm climates where heat stress during summer represents a concern. However, research is lacking on health-related parameters of calves raised in this type of hutch under summer temperatures in a subtropical climate. We hypothesized that dairy calves housed in the Calf-Tel hutches until weaning would adapt well during summer months and experience improved health compared with calves housed in traditional wire framed hutches. Therefore, the objective of the present study was to evaluate the health and performance of preweaned 
dairy calves housed in Calf-Tel hutches during summer under subtropical climatic conditions.

\section{MATERIALS AND METHODS}

\section{Animals and Animal Housing}

The study followed the University of Florida animal care committee guidelines and was conducted at a north-central Florida dairy farm during the summer of 2009. The climate, as described by a weather station close to the farm (Gilchrist County weather station, Bell, FL), is classified as subtropical with average ambient temperatures for the months of the study (June to August) ranging from 21.1 (minimum) to $32.2^{\circ} \mathrm{C}$ (maximum), with a relative average humidity $( \pm \mathrm{SD})$ of $92.9 \pm 15 \%$. One hundred female Holstein (HO) calves or Holstein- Jersey crosses $(\mathbf{H J})$ were enrolled in the study. Calves were separated from their dam within 2 $\mathrm{h}$ after birth and fed $3.8 \mathrm{~L}$ of colostrum that contained $>70 \mathrm{~g} / \mathrm{L}$ of IgG measured by the use of a colostrometer (Calloway et al., 2002), calves then had their navel dipped with an iodine solution and were identified by use of an ear tag. Treatment allocation was blocked by calf breed (HO, HJ) and calves were randomly assigned to either a wire hutch $(\mathrm{HO}, \mathrm{n}=24 ; \mathrm{HJ}=26)$ or a Calf-Tel hutch ( $\mathrm{HO}, \mathrm{n}=25$; HJ $=25)$ until weaning (9 wk of age). The wire hutches consisted of a rectangular $2-\mathrm{m}^{2}$ space enclosed with hog wire with a plywood roof. As commonly performed in Florida dairies, the wire hutches were situated over a sand floor located underneath parallel rows of tall trees $(>9 \mathrm{~m}$ in height) that were about $4 \mathrm{~m}$ apart, resulting in all animals having similar levels of partial natural shade through the entire day. The wire hutches were aligned in 2 rows oriented east-west, approximately $2 \mathrm{~m}$ apart. The Calf-Tel housing was constructed with polyethylene. The rear door provided superior airflow for ventilation and its opaque walls reduced the penetration of UV light; size was approximately $4 \mathrm{~m}^{2}\left(2 \mathrm{~m}^{2}\right.$ inside the hutch plus a wired $2-\mathrm{m}^{2}$ outside area). The Calf-Tel hutches were located in an open area, exposed to direct sun light, and arranged in rows oriented east-west.

Calves were managed the same across housing type and received 2 feedings of $3.8 \mathrm{~L}$ of colostrum during the first $24 \mathrm{~h}$ of life, then $3.8 \mathrm{~L}$ of pasteurized enriched hospital milk ( $13 \%$ total milk solids) daily until 7 wk of age. At wk 8, milk was provided only in the morning. At wk 9 calves were weaned. After $7 \mathrm{~d}$ of age, calves had ad libitum access to the starter diet described in Table 1, which met or exceeded the requirements for preweaned Holstein calves (NRC, 2001). Water from a plastic bucket $(7.6 \mathrm{~L})$, filled twice a day,
Table 1. Composition of the starter grain diet fed to the study calves

\begin{tabular}{lc}
\hline Nutrient content $^{1}$ & Starter grain \\
\hline $\mathrm{NE}_{\mathrm{G}}(\mathrm{Mcal} / \mathrm{kg})$ & 1.24 \\
$\mathrm{CP}(\%)$ & 22 \\
$\mathrm{Fat}(\%)$ & 2.5 \\
$\mathrm{ADF}$ & 10.5 \\
$\mathrm{Ca}(\%)$ & $0.9-1.3$ \\
$\mathrm{P}(\%)$ & 0.6 \\
$\mathrm{~S}(\%)$ & 0.00006 \\
Vitamin A $(\mathrm{IU} / \mathrm{kg})$ & 17,640 \\
Monensin $^{2}(\mathrm{~g} / \mathrm{t})$ & 60 \\
\hline
\end{tabular}

${ }^{1}$ Values were taken from company analysis; Purina, St. Louis, MO.

${ }^{2}$ Elanco Animal Health, Greenfield, IN.

was provided throughout the study from $2 \mathrm{~d}$ of age. Calves were dehorned before $30 \mathrm{~d}$ of age with electric cauterization under local anesthesia with veterinary supervision and vaccinated according to farm operational procedures established by the farm veterinarian. Briefly, the vaccination protocol for preweaned heifers included intranasal TSV-2 (IBR/PI3; Zoetis, Florham Park, NJ) at $2 \mathrm{~d}$; Clostridial 8-way (Zoetis) and BoviShiled Gold (IBR/PI3/BVD/BRSV; Zoetis) at 2 and 6 wk; and Ocu-guard MB-1 (Moraxella bovis; Boehringer Igelheim, St. Joseph, MO) at 7 wk. In addition, calves received $3 \mathrm{~mL}$ of Bo-Se (Se/vitamin E; Merck Animal Health, Millsboro, DE) at $2 \mathrm{~d}$ and Safe-Guard (Merck Animal Health) at 8 wk.

\section{Experimental Procedures}

Blood samples were collected from the jugular vein to measure serum total proteins (STP) concentration to determine failure of passive transfer in calves 2 to 7 d old using evacuated tubes without an anticoagulant (Becton Dickinson Vacutainer, Franklin Lakes, NJ). Samples were allowed to clot and serum was harvested for determination of STP concentration using a handheld refractometer (Calloway et al., 2002). Calf weight was measured soon after birth and at weaning using a digital scale (AllFlex New Zealand, Palmerston North, NZ). Calf pelvic height was measured at birth and at weaning using a height measurement stick (Nasco height stick, Fort Atkinson, WI). Rectal temperature, respiratory rate, and health scores were collected 3 times per week at 0900 and $1500 \mathrm{~h}$ until weaning. Rectal temperature was measured using a rectal thermometer (30-s digital thermometer, Lifelabs CSN Stores, Boston, MA). Respiratory rate was evaluated by counting the movements of the abdominal muscles in the flanks during respiration according to Spain and Spiers (1996). Health status was assessed following the calf health-scoring chart developed by the University 
of Wisconsin (McGuirk, 2008), which facilitated the screening of sick calves by evaluating fecal score, nasal discharge, eye discharge, and ear position as follows: fecal score $(0,1=$ normal; $2,3=$ diarrhea $)$, nasal score $(0,1=$ normal; $2,3=$ nasal discharge $)$, eye score $(0,1$ $=$ normal; $2,3=$ eye discharge, crusty eyes), and ear score $(0,1=$ normal; $2,3=$ head tilt, one ear or both ears dropped). Calves that scored the highest score of the scale or combinations of 2 or more abnormalities were further evaluated for treatment. Treatments were performed by farm personnel from the calf-rearing unit that were trained by the investigators using standardized diagnostic-treatment protocols to recognize and treat the most common calfhood diseases. Diagnostic skills of farm personnel were monitored closely by the investigators, and feedback was provided by assisting in diagnosis and treatment twice a week. Calves submitted for evaluation based on health scores were subject to physical examination including determination of body temperature, overall demeanor, hydration status, checking of fecal consistency, and lung auscultation. If no improvement was evident calves were checked by the attending veterinarian during the farm visit.

Two hutches, one from each housing type, were outfitted with a digital thermometer (Hobo Pro RH/Temp Sensors, Onset Computer Corporation, Bourne, MA) placed in the back of the hutch to assess the ambient temperature and relative humidity within the hutch. A third digital thermometer with a radiation shield was placed on a $1.8-\mathrm{m}$ pole to assess atmospheric temperature and relative humidity. Each digital thermometer had a plastic cap to prevent the thermometers from getting wet. The digital thermometer readings were recorded at 10-min intervals. A temperature humidity index (THI) was calculated using the formula [THI = $\mathrm{TD}-(0.05-0.55 \mathrm{RH}) \times(\mathrm{TD}-58)]$, where $\mathrm{TD}=$ daily temperature and $\mathrm{RH}=$ relative humidity (Kummar et al., 2008). A THI cut-off value of 77 was considered for categorization of this variable (Johnson et al., 1963). Rainfall (mm) during the month was also collected from a weather station close to the dairy operation (Gilchrist County weather station).

\section{Statistical Analysis}

Ambient and hutch temperatures were averaged for every 3 -h period. Calf rectal temperatures and respiratory rates were analyzed using repeated measures (PROC MIXED SAS Institute Inc., Cary, NC). The model included hutch type, breed, day, and hutch type by breed and hutch type by day interactions. Calf health scores (ears, eyes, nasal, coughing) and treatments were evaluated using logistic regression (PROC LOGISTIC).
The response variable for each of the scored health events was expressed as a binary trait (nonaffected $=0$; affected $=1$ ) based on our case definition. To avoid the complexity of the definition of a new case for repeated health events in the same calf (e.g., nasal discharge) and the issues raised by the potential correlation between health events within calf, calves with at least 1 health event were considered as affected in the logistic regression analysis. The final model included calf health score by hutch type and by breed. As diarrhea is a very common disorder in young calves, the time of occurrence of the first diarrhea event was analyzed using time-to-event analysis by the Kaplan-Meier method. Least squares means were estimated for ADG, weaning weight, and height by type of housing (PROC GLM). The model included hutch, breed, and the interaction between hutch and breed. Birth weight and height were used as covariates. Statistical significance was set at values of $P<0.05$.

\section{RESULTS AND DISCUSSION}

\section{Climatic Data}

The summarized climatic data are shown in Table 2. To evaluate the stressor effect of temperature over the physiological status of an animal several indices have been proposed, such as the THI (Wilson, 1971; Berman, 2005). During the study period, the ambient THI ranged from 73.5 to 84.3 units. The greatest THI were recorded during July, with 84.3, 83.5, and 84.4 units for wire, Calf-Tel, and ambient THI, respectively. Of the 90 experimental days, the numbers of days that THI values exceeded 77 units (considered here as a cut-off value in the categorization) were 69,64 , and 68 for wire, Calf-Tel, and ambient, respectively. A 10-d period of consecutive THI values above 81 units was recorded in August (64 to 74 experimental days) for the 3 environments. Over a 24 -h period, calves were exposed to a THI $>77$ units for $18 \mathrm{~h}$, ranging from 77 to 82 THI units from 0900 to $1200 \mathrm{~h}$.

The THI estimates the magnitude of heat stress. In adult Holstein cows, the THI above which milk yield declines was estimated at 72 to 77 (Johnson et al., 1963; Bohmanova et al., 2007), whereas the THI above which rectal temperature increases was estimated at 78 (Dikmen and Hansen, 2009). The high THI values recorded in the current study (above 77) may explain the elevated rectal temperatures and respiratory rates in calves during the afternoon recording (especially in Calf-Tel hutches), as this may be a physiological response to the high ambient temperature and humidity. In agreement with this idea, Theurer et al. (2014) re- 
Table 2. Mean and SE for temperature humidity index (THI) and average precipitation for experimental months from June to August

\begin{tabular}{lcccc}
\hline Month $^{1}$ & $\begin{array}{c}\text { Ambient } \\
\text { THI }^{2}\end{array}$ & $\begin{array}{c}\text { Calf-Tel }^{3} \text { hutch } \\
\text { THI }\end{array}$ & $\begin{array}{c}\text { Wire hutch } \\
\text { THI }\end{array}$ & $\begin{array}{c}\text { Precipitation }^{4} \\
(\mathrm{~mm})\end{array}$ \\
\hline June & $78.0 \pm 0.07$ & $77.1 \pm 0.07$ & $77.6 \pm 0.07$ & 147.8 \\
July & $80.1 \pm 0.06$ & $78.9 \pm 0.06$ & $79.7 \pm 0.07$ & 193.0 \\
August & $79.5 \pm 0.05$ & $78.7 \pm 0.06$ & $79.2 \pm 0.06$ & 202.4 \\
\hline
\end{tabular}

${ }^{1}$ Weather data collected from June 1 to August 31, 2010.

${ }^{2} \mathrm{THI}=\mathrm{TD}-(0.55-0.55 \mathrm{RH}) \times(\mathrm{TD}-58)$, where $\mathrm{TD}=$ daily temperature and $\mathrm{RH}=$ relative humidity. Means and SE were calculated using data recorded with black globe weather thermometers located in one hutch of each type and in one 1.8-m pole (protected by a radiation shield).

${ }^{3}$ L. T. Hampel Corp., Germantown, WI.

${ }^{4}$ Weather station at Gilchrist County, Florida.

ported a significant positive association between rectal temperature and THI in 6-mo-old crossbred heifers, and Mader et al. (2006) identified a positive correlation between THI and panting score. However, in contrast to lactating dairy cows, the THI in calves above which performance and health is affected is not known and warrants research.

Accumulative rain fall of $543.2 \mathrm{~mm}$ was recorded for the $85 \mathrm{~d}$ of the experiment. August was the month with the highest rainfall of $202.4 \mathrm{~mm}$, followed by July with $193 \mathrm{~mm}$ and June with $147.8 \mathrm{~mm}$.

\section{Health and Performance}

Ninety-six calves completed the study, 48 calves in each group. Four calves, 2 from each group, were excluded from the final results because of incomplete data. Calf distribution according to hutch type, breed and average STP, birth and weaning weight, ADG, and weaning height are presented in Table 3.

Serum total proteins were measured as an indirect indicator of serum IgG concentrations to assess an adequate colostrum intake for attainment of passive transfer of immunity (Calloway et al., 2002). Table 3 shows the STP values for calves according to hutch type. Average STP were $5.82 \pm 0.13$ and $6.05 \pm 0.14 \mathrm{~g} /$ $\mathrm{dL}(P>0.05)$ for wire and Calf-Tel hutches, respectively. These STP values indicate that calves in the study were not immunocompromised (Donovan et al., 1998), despite being born during summer when colostrum absorption has been reported to be inferior compared with winter (Donovan et al., 1998; Nardone et al., 2006). In the study farm, colostrum was collected, evaluated for quality, and frozen for future use. Calves in our study received thawed colostrum that contained $>70 \mathrm{~g} / \mathrm{L}$ of IgG. Mortality in the study was not analyzed because of low incidence ( 2 calves per group).

Rectal temperatures in calves measured at $0900 \mathrm{~h}$ did not differ $(P>0.05)$ between wire hutches and Calf-Tel, at $38.8 \pm 0.29$ and $39.1 \pm 0.22^{\circ} \mathrm{C}$, respectively. However, at $1500 \mathrm{~h}$, average rectal temperatures in calves raised in wire hutches were lower compared with calves in the Calf-Tel hutches, at $39.1 \pm 0.22$ and 40.1 $\pm 0.28^{\circ} \mathrm{C}(P<0.05)$, respectively. Rectal temperature ranges in our study agreed with those of Lammers et al., (1996), where average rectal temperature was 39.6 $\pm 0.05^{\circ} \mathrm{C}$, and Macaulay et al. (1995), who reported average rectal temperature of $38.8 \pm 0.14^{\circ} \mathrm{C}$ for calves reared in Calf-Tel hutches during the fall. In contrast to calves in Calf-Tel hutches, calves in the wire hutches were not protected from the rain and, although this was not measured in our study, it is likely that they were wetter than calves in Calf-Tel hutches. Kelly et al. (1984), found that wet laying surface and skin increases heat loss from calves. However, it is debatable that this is the case when ambient temperature and humidity are

Table 3. Average $( \pm \mathrm{SE})$ calf serum total proteins, weaning weight, and height according to housing type [Calf-Tel (L. T. Hampel Corp., Germantown, WI) and wire hutch] and breed (Holstein and Holstein-Jersey cross)

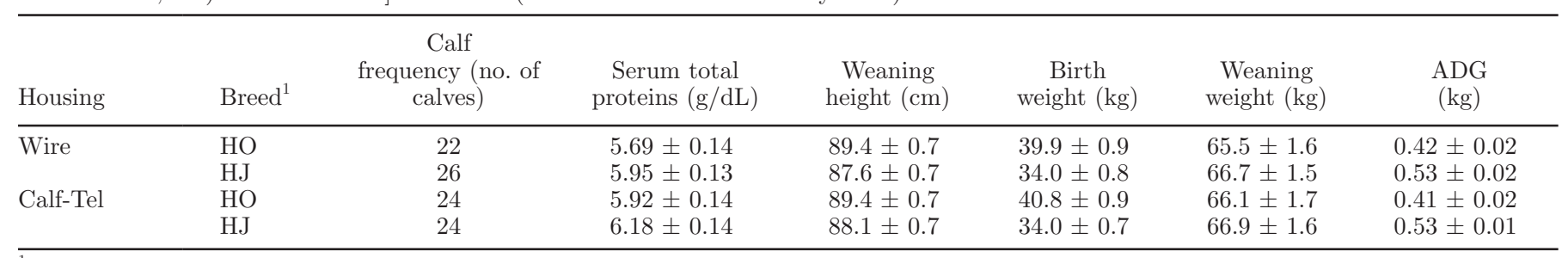

${ }^{1} \mathrm{HO}=$ Holstein; HJ = Holstein-Jersey cross. 


\section{A: Respiratory rate at 0900 (AM)}

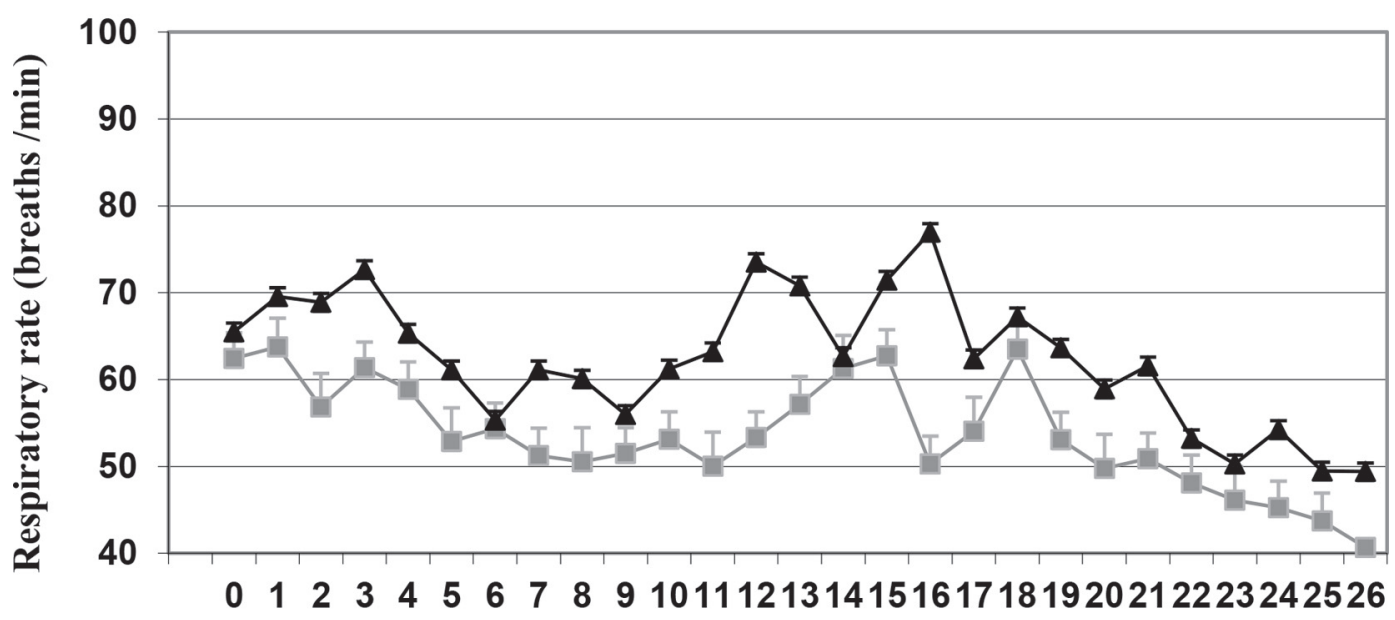

\section{B: Respiratory rate at $1500 \mathrm{~h}(\mathrm{PM})$}

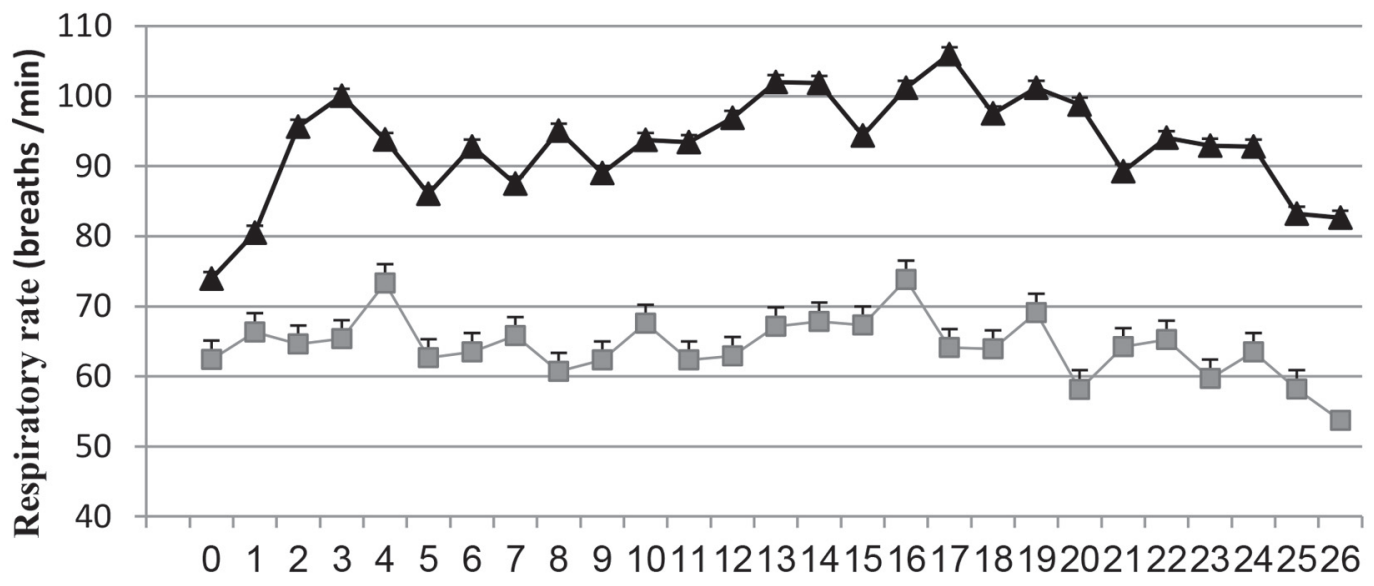

\section{Evaluation number (3 times/wk)}

Figure 1. Respiratory rate in calves during the morning (0900 h; A) and afternoon (1500 h; B) for wire (squares) and Calf-Tel (L. T. Hampel Corp., Germantown, WI; triangles) hutches. Calves were evaluated 3 times per week.

high, unless air movement is increased (fans) to promote evaporation (West, 2003). The variations in respiratory rate by type of hutch and time are reported in Figure 1. Throughout the experiment, calves in Calf-Tel hutches had higher respiratory rates compared with calves in the wire hutches, and increased respiratory rates in the afternoon coincided with elevated temperatures during that time for calves in Calf-Tel hutches. Similar to rectal temperatures, respiratory rates in calves housed in both types of hutches were not different at $0900 \mathrm{~h}$. However, at $1500 \mathrm{~h}$, respiratory rates of calves in CalfTel hutches $(90 / \mathrm{min})$ were 30 breaths per minute higher than calves in wire hutches with a significant hutch by time interaction $(P<0.05)$. These results are similar to those found by Lammers et al. (1996) for calves reared in polyethylene hutches, where the afternoon elevated respiratory rate for calves housed in Calf-Tel hutches could be attributed to the physiological adaptation to dissipate heat through expired air (Robertshaw, 2006). Conversely, lower respiratory rates in calves in wire hutches agree with Lammers et al. (1996) observations that supplemental shade reduces respiratory rate.

Frequencies for calf health events are shown in Table 4. Overall morbidity in calves expressed as percentage of total animals was $29.1,66.6,58.3$, and $29.2 \%$ for ear, eyes, nasal, and coughing, respectively. Detectable differences were noted for the proportions of calves showing signs of disease between Calf-Tel and wire hutches. 
Table 4. Frequency of affected calves by health event based on categorization of health scores and proportions receiving veterinary treatment by hutch type [Calf-Tel (L. T. Hampel Corp., Germantown, WI) and wire] and breed (Holstein and Holstein-Jersey cross)

\begin{tabular}{|c|c|c|c|c|c|}
\hline Item & $\begin{array}{c}\operatorname{Ear}^{1} \\
{[\mathrm{n}(\%)]}\end{array}$ & $\begin{array}{c}\text { Eyes }^{2} \\
{[\mathrm{n}(\%)]}\end{array}$ & $\begin{array}{l}\text { Nasal }^{3} \\
{[\mathrm{n}(\%)]}\end{array}$ & $\begin{array}{l}\text { Coughing }^{4} \\
{[\mathrm{n}(\%)]}\end{array}$ & $\begin{array}{c}\text { Veterinary } \\
\text { treatment }^{5} \\
{[\mathrm{n}(\%)]}\end{array}$ \\
\hline Total cases & $28(29.1)$ & $64(66.6)$ & $56(58.3)$ & $28(29.2)$ & $43(44.8)$ \\
\hline Wire $(\mathrm{n}=48)$ & $18(37.5)$ & $27(56.2)$ & $34(70.8)$ & $19(29.2)$ & $31(64.5)$ \\
\hline Holstein $(\mathrm{n}=22)$ & $8(36.3)$ & $12(54.5)$ & $15(68.1)$ & $8(36.3)$ & $13(59)$ \\
\hline $\mathrm{HJ}^{6}(\mathrm{n}=26)$ & $10(38.4)$ & $15(57.6)$ & $19(73.0)$ & $11(42.3)$ & $18(69.2)$ \\
\hline Calf-Tel $(\mathrm{n}=48)$ & $10(20.8)$ & $37(77.0)$ & $22(45.8)$ & $9(18.7)$ & $12(25)$ \\
\hline Holstein $(\mathrm{n}=24)$ & $7(29.1)$ & $18(75.0)$ & $11(45.8)$ & $6(25.0)$ & $4(16.6)$ \\
\hline HJ $(\mathrm{n}=24)$ & $3(12.5)$ & $19(79.1)$ & $11(45.8)$ & $3(12.5)$ & $8(33.3)$ \\
\hline
\end{tabular}

${ }^{1}$ One or both ears were droopy.

${ }^{2}$ Lacrimation or crusty eyes.

${ }^{3}$ Mucous or mucopurulent discharge.

${ }^{4}$ Spontaneous coughing during evaluation.

${ }^{5}$ Criteria for veterinary treatment based on standardized diagnostic-treatment protocols.

${ }^{6}$ Holstein-Jersey cross

A logistic model was used to calculate the odds of heifers of being classified as affected by a disease symptom for calves reared in the wire hutches compared with calves reared in the Calf-Tel hutches. Odds ratios for health score evaluations are shown in Table 5. Ear scores did not differ between calves in Calf-Tel or wire hutches. Abnormal eye scores were less likely to occur for calves in the wire hutches. However, signs of respiratory disease, such as nasal discharge and coughing, were higher for calves in the wire hutches compared with calves in Calf-Tel hutches, and the odds of health scores indicative of disease were higher for wire hutches for nasal and coughing evaluations. Overall, calves in the wire hutches had greater odds (odds ratio $=5.47$; $95 \% \mathrm{CI}=2.26$ to 13.2 ) of receiving veterinary treatment compared with calves in the Calf-Tel hutches.

Diarrhea is a common disease during the first $2 \mathrm{wk}$ of a calf's life. A Kaplan-Meier survival distribution for diarrhea, shown in Figure 2, indicates that about $75 \%$ of the calves experienced at least one episode of diarrhea from birth to weaning. However, no differences were observed in the incidence or duration of diarrhea in calves between hutch types. Weaning weights $(66.5$ \pm 1.5 and $66.4 \pm 1.5 \mathrm{~kg}$ for Calf-Tel and wire hutches, respectively; $P>0.05)$ and $\mathrm{ADG}(0.47 \pm 0.02$ and 0.48 $\pm 0.02 \mathrm{~kg}$ for Calf-Tel and wire hutches, respectively; $P$ $>0.05)$ were not affected by hutch type. As expected, birth weights were lower for HJ calves compared with HO calves in both housing systems. However, weaning weight was not affected by breed $(P>0.05)$, indicating that the amount of milk provided likely restricted to some extent the growth in $\mathrm{HO}$ calves. Average weaning weight for $\mathrm{HO}$ calves in Calf-Tel hutches was $66.1 \pm$ $1.7 \mathrm{~kg}$, compared with $65.5 \pm 1.6 \mathrm{~kg}$ for $\mathrm{HO}$ calves in wire hutches. Weaning weights for HJ were $66.9 \pm$ 1.6 and $66.7 \pm 1.5 \mathrm{~kg}$ in Calf-Tel and wire hutches, respectively. Some controversy exists in the literature as to what ambient temperature calves experience detrimental effects on growth. Nardone et al., (2006) reported that temperatures between 15 and $29^{\circ} \mathrm{C}$ did not affect growth performance, whereas Stull and Reynolds (2008) reported that the upper critical ambient temperature that affects growth in calves is around $25^{\circ} \mathrm{C}$. In the current study, the consistent higher levels for rectal temperatures and respiratory rates at $1500 \mathrm{~h}$ for calves in the Calf-Tel did not affect weaning weights or weaning heights $(P>0.05)$.

Table 5. Odds ratios for health score evaluation indicative of disease for calves in wire hutches compared with calves in Calf-Tel (L. T. Hampel Corp., Germantown, WI) hutches (Calf-Tel hutches are considered as reference)

\begin{tabular}{lccc}
\hline $\begin{array}{l}\text { Health } \\
\text { variable }\end{array}$ & $\begin{array}{l}\text { Odds } \\
\text { ratio }\end{array}$ & $95 \% \mathrm{CI}^{1}$ & $P$-value \\
\hline Eyes $^{2}$ & 0.38 & $0.16-0.92$ & 0.03 \\
Ears $^{3}$ & 2.28 & $0.92-5.66$ & $>0.05$ \\
Nasal $^{4}$ & 2.87 & $1.24-6.66$ & 0.01 \\
Coughing $^{5}$ & 2.83 & $1.12-7.18$ & 0.02 \\
Treatment $^{6}$ & 5.47 & $2.26-13.2$ & 0.0005 \\
\hline
\end{tabular}

${ }^{1}$ Confidence intervals that do not contain 1 indicate significant odds ratios.

${ }^{2}$ Include those calves with lacrimation or crusty eyes.

${ }^{3}$ Ears score indicate that one or both ears were droopy.

${ }^{4}$ Nasal score refers to mucous or mucopurulent nasal discharge.

${ }^{5}$ Coughing was recorded as calves spontaneous coughing at the time when other variables were recorded.

${ }^{6}$ Includes all veterinary treatments. 


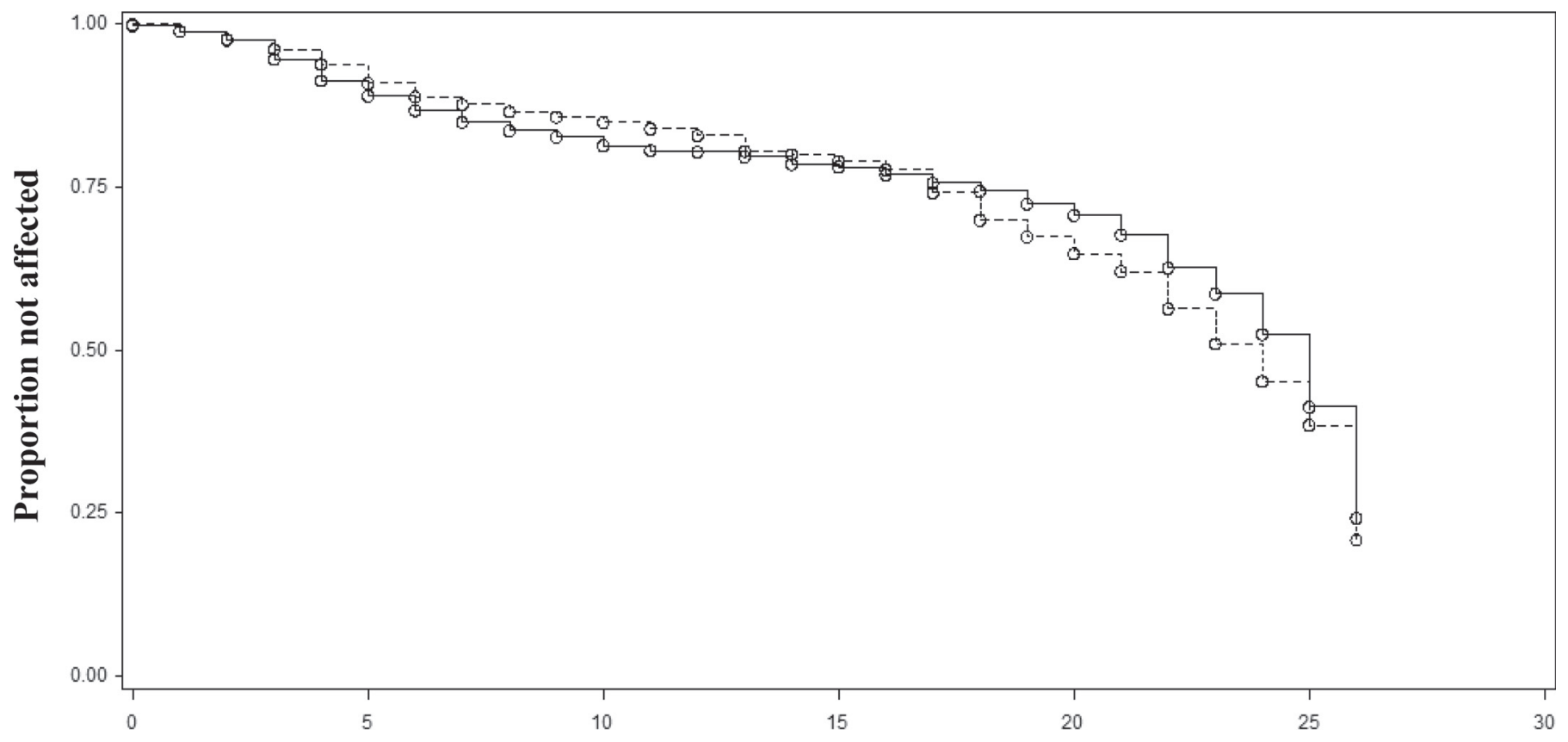

\section{Evaluation number (3 times/wk)}

Figure 2. Kaplan-Meier curve showing survival proportion of 96 calves stratified according to occurrence of the first diarrhea event in calves in the Calf-Tel (L. T. Hampel Corp., Germantown, WI; - ) and wire hutches (- - ) during the study. Wilcoxon test of equality of strata, $\chi^{2}=$ $5.04(P>0.05)$. Calves were evaluated 3 times per week and evaluations are presented in sequential order from 0 to 26.

\section{CONCLUSIONS}

Despite experiencing higher rectal temperatures and respiratory rates at $1500 \mathrm{~h}$, preweaning health and growth were not affected in calves reared in Calf-Tel hutches. The lack of difference in weight gain and the lower frequency of calves with abnormal health scores and receiving veterinary treatment in the Calf-Tel hutches compared with traditional wire-framed hutches suggests that this housing system adapted well to the specific environmental conditions of our study.

\section{ACKNOWLEDGMENTS}

The authors thank the DPS-Florida-Bell Dairy farm (Bell, FL), for the use of their facilities, animals, collaboration, and assistance. We acknowledge the valuable assistance of students and residents during this experiment. Our special recognition to Elizabeth D'Agosto (University of Florida) for her valuable help in collecting and organizing data.

\section{REFERENCES}

Berman, A. 2005. Estimates of heat stress relief needs for Holstein dairy cows. J. Anim. Sci. 83:1377-1384.
Bohmanova, J., I. Misztal, and J. B. Cole. 2007. Temperature-humidity index as indicator of milk production losses due to heat stress. J. Dairy Sci. 90:1947-1956.

Broucek, J., P. Kisac, and M. Uhrincat. 2009. Effect of hot temperatures on the hematological parameters, health and performance of calves. Int. J. Biometeorol. 53:201-208.

Calloway, C. D., J. W. Tyler, R. K. Tessman, D. Hostetler, and J. Holle. 2002. Comparison of refractometers and test endpoints in the measurement on serum protein concentration to assess passive transfer status in calves. J. Am. Vet. Med. Assoc. 221:1605-1608.

Collier, R. J., D. K. Beede, W. W. Thatcher, L. A. Israel, and C. J. Wilcox. 1982. Influences of environment and its modifications on dairy health and production. J. Dairy Sci. 65:2213-2227.

Dikmen, S., and P. J. Hansen. 2009. Is the temperature-humidity index the best indicator of heat stress in lactating dairy cows in a subtropical environment? J. Dairy Sci. 92:109-116.

Donovan, G. A. 1992. Management of cow and newborn calf at calving. Page 398 in Large Dairy Herd Management. H. H. Van Horn and C. J. Wilcox, ed. American Dairy Science Association, Champaign, IL.

Donovan, G. A., I. R. Dohoo, D. M. Montgomery, and F. L. Benett. 1998. Associations between passive immunity and morbidity and mortality in dairy heifers in Florida, USA. Prev. Vet. Med. 34:31-46.

Johnson, H. D., A. C. Ragsdale, I. L. Berry, and M. D. Shanklin. 1963. Temperature-humidity effects including influence of acclimation in feed and water consumption of Holstein cattle. Missouri Agric. Exp. Sta. Res. Bul. 846. University of Missouri, Columbia.

Kelly, T. G., V. A. Dodd, D. J. Ruane, R. J. Fallon, and P. J. Tuite. 1984. An assessment of the influence of some house designs and environmental factors on calf performance. J. Agric. Eng. Res. 30:175-184.

Kummar, S. S., K. N. Wadhwani, K. Khanna, and A. M. Patel. 2008. Effects of quality feeds and litter materials on broilers performance under hot humid climate. Int. J. Poult. Sci. 7:14-22. 
Lammers, B. P., J. W. vanKoot, A. J. Henrichs, and R. E. Graves 1996. The effect of plywood and polyethylene calf hutches on heat stress. Appl. Eng. Agric. 12:741-745.

Macaulay, A. S., G. L. Hahn, D. H. Clark, and D. V. Sisson. 1995. Comparison of calf housing types and tympanic temperature rhythms in Holstein calves. J. Dairy Sci. 78:856-862.

Mader, T. L., M. S. Davis, and T. Brown-Brandl. 2006. Environmental factors influencing heat stress in feedlot cattle. J. Anim. Sci. $84: 712-719$.

McGuirk, S. M. 2008. Disease management of dairy calves and heifers. Vet. Clin. North Am. Food Anim. Pract. 24:139-153.

NAHMS. 2007. Heifer calf health and management practices on U.S dairy operations, 2007. Accessed Mar. 1, 2015. www.aphis.usda. gov/animal_health/nahms/ dairy/downloads/dairy07.

Nardone, A., B. Ronchi, N. Lacetera, and U. Bernabucci. 2006. Climatic effects on productive traits in livertock. Vet. Res. Commun. 30:75-81

NRC. 2001. Nutrient Requirements of Dairy Cattle. 7th rev. ed. Natl. Acad. Sci., Washington, DC.
Robertshaw, D. 2006. Mechanisms for the control of respiratory evaporative heat loss in panting animals. J. Appl. Physiol. 101:664-668.

Spain, J. N., and D. E. Spiers. 1996. Effects of supplemental shade on thermoregulatory response of calves to heat challenge on heat environment. J. Dairy Sci. 79:639-646.

Stull, C., and J. Reynolds. 2008. Calf welfare. Vet. Clin. North Am. Food Anim. Pract. 24:191-203.

Theurer, M. E., D. E. Anderson, B. J. White, M. D. Miesner, and R. L. Larson. 2014. Effects of weather variables on thermoregulation of calves during periods of extreme heat. Am. J. Vet. Res. $75: 296-300$.

West, J. W. 2003. Effects of heat stress on production in dairy cattle. J. Dairy Sci. 86:2131-2144.

Wilson, W. O. 1971. Evaluation of stressor agents in domestic animals. J. Anim. Sci. 32:578-583.

Young, B. A. 1983. Ruminant cold stress: Effect on production. J. Anim. Sci. 57:1601-1607. 